\title{
Managing Co-Morbid Asthma With Allergic Rhinitis: Targeting the One-Airway With Leukotriene Receptor Antagonists
}

\author{
Erkka Valovirta, $M D, P h D$
}

\begin{abstract}
Allergic rhinitis is a common inflammatory condition affecting upper airways, nose, and eyes. Allergic rhinitis is a global health problem and is increasing in prevalence. Allergic rhinitis patients have often comorbidities asthma being one of the most common. Up to $40 \%$ of patients with allergic rhinitis have asthma and at least as many as $80 \%$ of asthma patients experience symptoms of allergic rhinitis. Patients with persistent allergic rhinitis should be evaluated for asthma, and patient with asthma should be properly evaluated for rhinitis. Allergic rhinitis and its impact on asthma update is proposing that treatments for one condition, one airwayone disease, may alleviate the coexisting conditions. Patients need early recognition, proper diagnosis, effective treatment, and followup. The treatment should be a combined strategy to treat the upper and lower airways for a good efficacy/safety ratio.
\end{abstract}

Key Words: allergic rhinitis, ARIA, asthma, one airway, leukotriene receptor agonist

(WAO Journal 2012; 5:S210-S211)

\section{INTRODUCTION AND BACKGROUND}

$T^{1}$ he burden of allergic rhinitis is evident not only by its prevalence but also by its impact on individuals and the society ${ }^{1-3}$ Allergic rhinitis is a common inflammatory condition affecting upper airways, nose, and eyes. Allergic rhinitis is a global health problem and is increasing in prevalence. The prevalence of self-reported allergic rhinitis among randomly identified people in Europe is $24.5 \%{ }^{4}$

Allergic rhinitis patients have often comorbidities asthma being one of the most common. Up to $40 \%$ of patients with allergic rhinitis have asthma and at least as many as $80 \%$ of asthma patients experience symptoms of allergic rhinitis. Allergic rhinitis is one of the multiple risk factors for the development of asthma both for adults and children. 5,6

Allergic rhinitis increases the risk of asthma hospitalizations; a retrospective cohort study was conducted to determine the incremental effect of allergic rhinitis on

\footnotetext{
From the Turku Allergy Center, Finland.

Based on the presentation given at the BANYU Symposium at the 20th, World Allergy Congress in Bangkok in December 2007.

Correspondence to: Erkka Valovirta, MD, PhD, Turku Allergy Center, Finland. Telephone: +358 3063 33000. Fax: +358 3063 36002. E-mail: erkka. valovirta@terveystalo.com.

Copyright (c) 2012 by World Allergy Organization
}

healthcare resource use in adults with asthma in UK. ${ }^{7}$ During the 12-month follow-up period of 27,303 patients (16 to 55 years of age), patients with documented allergic rhinitis were significantly more likely to be hospitalized for asthma than were patients with asthma alone $(P=0.0058)$. The same study showed also that patients with allergic rhinitis filled significantly more prescriptions for short-acting beta2-agonists than did patients with asthma alone $(P<0.0001)$. In addition, multivariate analysis from the same cohort showed that a concomitant diagnosis of allergic rhinitis was a significant predictor of higher annual costs for asthma medications $(P=0.0001)$. The incidence of asthma attacks was significantly $(P=0.046)$ higher among patients with both asthma and allergic rhinitis than among patients with asthma alone according a survey including 1490 adults with chronic asthma. ${ }^{8}$ This survey also showed that the incidence of emergency room visits was more than twice as high among patients with both asthma and allergic rhinitis than among patients with asthma alone.

A survey including children with asthma and comorbid allergic rhinitis in general practice in UK showed that presence of concomitant allergic rhinitis with asthma increases annual number of physician visits $(P<0.0001)$ and likelihood of hospitalizations $(P=0.0011) .{ }^{9}$ This survey also showed the increased use of short-acting beta2-agonists $(P<0.0001)$, increased use of oral corticosteroids $(P<$ $0.0001)$ and increased asthma drug costs $(P<0.0001)$ in children with allergic rhinitis and asthma.

Patients with persistent allergic rhinitis should be evaluated for asthma, and patient with asthma should be properly evaluated for rhinitis. Allergic rhinitis and its impact on asthma (ARIA) update is proposing that treatments for one condition, one airway-one disease, may alleviate the coexisting conditions. ${ }^{1}$ This is one of the major goals also in the Finnish Allergy Programme 2008-2018 to decrease the burden of allergic asthma and rhinitis in the society. ${ }^{10}$ Patients need early recognition, proper diagnosis, effective treatment, and followup. The treatment should be a combined strategy to treat the upper and lower airways for a good efficacy/safety ratio.

\section{DOES TREATMENT OF ALLERGIC RHINITIS EFFECT ON ASTHMA?}

Van Cauwenberge et al reviewed. ${ }^{11}$ the literature thoroughly and came to the conclusion that the treatment of 
allergic rhinitis in asthma patients has been shown to improve asthma symptoms, pulmonary functions tests, and to reduce costs. The risk of emergency room treatment or hospitalizations, exercise-induced asthma, or bronchial hyperresponsiveness were also shown to reduce. Furthermore, inadequately controlled allergic rhinitis in asthmatic patients can contribute toward increasing asthma exacerbations and poorer symptom control. These may increase medical resource use. In the same review van Cauwenberge et al. ${ }^{11}$ state that leukotriene modifiers are effective in controlling the symptoms of mild to moderate asthma and the symptoms of rhinitis, ${ }^{12}$ and the use of asthma and rhinitis medication is reduced. ${ }^{13}$ However, a large number of patients form several studies was needed to show a $5 \%$ difference form placebo.

\section{IS A COMBINATION OF DIFFERENT THERAPIES MORE EFFECTIVE THAN A SINGLE THERAPY IN ASTHMA PATIENTS WITH ALLERGIC RHINITIS?}

The review by van Cauwenberge targeted also this question. ${ }^{11}$ The study by Nathan et al. ${ }^{14}$ evaluated patient with persistent asthma treated with the combination of fluticasone propionate and salmeterol. Adding montelukast or fluticasone propionate aqueous nasal spray for the treatment of seasonal allergic rhinitis resulted in no additional improvements in overall asthma control compared with the combination therapy with fluticasone and salmeterol alone. The association of budesonide nasal steroid with a leukotriene modifier, zafirlukast, was more effective for controlling nasal symptoms and especially bronchial symptoms than association of a nasal budesonide with loratadine plus pseudoephed-rine. ${ }^{15}$ Dahl et al have shown that in patients with pollen-induced allergic rhinitis and asthma the combination of nasal and inhaled glucocorticosteroids is needed to control the seasonal increase in nasal and lung symptoms. ${ }^{16}$

Controlled studies by Walsh ${ }^{17}$ and by Wilson ${ }^{18}$ show that the combination therapy with antihistamines and antileukotrienes is as effective as corticosteroid use in patients with allergic asthma and seasonal allergic rhinitis. The study by Roquet et $\mathrm{al}^{19}$ gives evidence in favor of the use of antileukotrienes to treat asthma and rhinitis. However, more data are needed to understand their full capacity. The combination of antileukotriene and antihistamine produces an inhibition of allergen-induced early and late phase airway obstruction in asthmatics.

Price at $\mathrm{al}^{20}$ showed that in asthmatics with allergic rhinitis a combination of montelukast and budesonide resulted significantly greater but limited efficacy in reducing airway obstruction when compared with doubling the dose of budesonide.

\section{CONCLUSIONS}

Allergic rhinitis and asthma often coexist, suggesting the concept of "one airway, one disease." This is because allergy is a systemic disease, which causes symptoms in different target organs. The most important factor in understanding the nature of asthma and allergy is to understand the inflammatory reaction involved in these diseases. Allergic inflammation causes symptoms and has to be controlled as well as possible with treatment. Whether or not treating allergic rhinitis improves asthma per se, it is important to recognize and treat allergic rhinitis in patients with asthma to improve there symptoms and quality of life.

\section{REFERENCES}

1. Bousquet J, Khaltaev N, Cruz AA, Denburg J, Fokkens WJ, et al. Allergic Rhinitis and Its Impact on Asthma (ARIA) 2008 Update. Allergy. 2008;63(Suppl. 86):8-160.

2. Canonica GW, Bousquet J, Mullol J, Scadding GK, Virchow JC. A survey of the burden of allergic rhinitis in Europe. Allergy. 2007;62 (Suppl. 85):17-25.

3. Valovirta E, Myrseth S-E, Palkonen S. The voice of the patients: allergic rhinitis is not a trivial disease. Curr Opin Allergy Clin Immunol. 2008;8: $1-9$.

4. Dahl R, Andersen PS, Chivato T, Valovirta E, de Monchy J. National prevalence of respiratory allergic disorders. Respir Med. 2004;98:398-403.

5. Guerra S, Sherrill DL, Marinez FD, Barbee RA. Rhinitis as an indepen dent risk factor for adult-onset asthma. J Allergy Clin Immunol. 2002; 109:419-425.

6. Wright AL, Holber CJ, Martinez FD, Halonen M, Morgan W, Taussig LM. Epidemiology of physician-diagnosed allergic rhinitis in childhood. Pediatrics. 1994;94:895-901.

7. Price D, Zhang Q, Kocevar VS, Yin DD, Thomas M. Effect of a concomitant diagnosis of allergic rhinitis on asthma-related health care use of adults. Clin Exp Allergy. 2005;35:282-287.

8. Bousquet J, Gaugris S, Kocevar VS, Zhang Q, Yin DD, Polos PG, Bjermer L. Increased risk of asthma attacks and emergency visits among asthma patients with allergic rhi nitis: a subgroup analysis of the investigation of montelukast as a partner agent for complementary therapy. Clin Exp Allergy. 2005;35:723-727.

9. Thomas M, Kocevar VS, Yin D, Price DB. Health care resource use by children with asthma and co-morbid allergic rhinitis in general practice in the United Kingdom. Pediatrics. 2005;115:129-134.

10. Haahtela T, von Hertzen L, Mäkelä M, Allergy Programme Working Group. Finnish Allergy Programme 2008-2018: time to act and change the course. Allergy. 2008;63:634-645.

11. van Cauwenberge P, Watelet J-B, van Zele T, Wang DY, Toskala E, et al. Does rhinitis lead to asthma? Rhinology. 2007;45:112-121.

12. Perry TT, Corren J, Philip G, Kim EH, Conover-Walker MK, et al. Protective effect of montelukast on lower and upper respiratory tract responses to short-term cat allergen exposure. Ann Allergy Asthma Immunol. 2004;93:431-438.

13. Virchow JC, Bachert C. Efficacy and safety of montelukast in adults with asthma and allergic rhinitis. Respir Med. 2006;11:1952-1959.

14. Nathan RA, Yancey SW, Waitkus-Edwards K, Prillaman BA, Stauffer JL, Philpot E, Dorinsky PM, Nelson HS. Fluticasone nasal spray is superior to montelukast for allergic rhinitis while neither affects overall asthma control. Chest. 2005;128:1910-1920.

15. Benitez HH, Arvizu VM, Gutierrez DJ. Nasal budesonide plus zafirlukast vs nasal budesonide plus loratadine-pseudoephedrine for controlling the symptoms of rhinitis and asthma. Rev Alergol MEx. 2005;52:90-95.

16. Dahl R, Nielsen LP, Kips J, Foresi A, Cauwenberge P, et al. Intranasal and inhaled fluticasone propionate for pollen-induced rhinitis and asthma. Allergy. 2005;60:875-881.

17. Walsh GM. Second-generation antihistamines in asthma therapy: is there a protective effect. Am J Respire Med. 2002;1:27-34.

18. Wilson AM. Are antihistamines useful in managing asthma? Allergy Clin Immunol. 2002;2:53-59.

19. Roquet A, Dahlén B, Kumlin M, Ihre E, Anstren G, Binks S, Dahlén SE. Combined antagonism of leukotrienes and histamine produces predom inant inhibition of allergen-induced early and late phase airway obstruc tion in asthmatics. Am J Respir Cri Care Med. 1997;155:1856-1863.

20. Price DB, Swern A, Tozzi CA, Philip G, Polos P. Effect of montelukast on lung function is asthma patients with allergic rhinitis: analysis from COMPACT trial. Allergy. 2006;61:737-742. 